\title{
AUTO-ORGANIZAÇÃO DE MULHERES E SAÚDE: UMA ANÁLISE SOBRE A EDUCAÇÃO POPULAR EM OFICINAS DE SAÚDE
}

\author{
Daniela Cristina Pereira Ramos, Universidade Federal de Campina Grande (UFCG) \\ dannielacristinna@gmail.com \\ Bruna Araújo de Sá, Universidade Federal de Campina Grande (UFCG) \\ brunnadesaa@gmail.com \\ Sofia Dionizio Santos, Universidade Federal de Campina Grande (UFCG) \\ psycosofya@hotmail.com
}

\begin{abstract}
RESUMO
Discorremos sobre as diferentes práticas pedagógicas que perpassam o projeto de extensão "Auto-organização de mulheres e saúde", tendo em vista que a educação popular torna-se componente primordial e indispensável na realização das oficinas do projeto. Nestas práticas destacamos a utilização de recursos didáticos e metodologias como importantes instrumentos motivadores, facilitadores da aprendizagem em saúde. Desenvolvemos levantamento bibliográfico, análise dos relatórios de vigências anteriores do projeto, e análise da experiência da oficina "Saúde da mulher, corpo e sexualidade". Abordamos a discussão acerca das práticas pedagógicas e da importância da educação popular em saúde. Concluímos que as práticas pedagógicas que norteiam as oficinas promovidas pelo projeto propiciam a todas as envolvidas a construção de saberes, tomando como ponto de partida o planejamento e as ações educativas sobre os temas abordados nas oficinas.
\end{abstract}

PALAVRAS-CHAVE: Educação popular; práticas pedagógicas; saúde.

\section{INTRODUÇÃO}

O Projeto de Extensão "Auto-organização de Mulheres e Saúde" está vinculado à Unidade Acadêmica de Ciências da Vida (UACV), no Centro de Formação de Professores (CFP) da Universidade Federal de Campina Grande, em Cajazeiras-PB. Em sua vigência no ano de 2017, o Projeto é coordenado pela Professora Sofia Dionizio Santos, com a colaboração das extensionistas Bruna Araújo de Sá,(acadêmica do curso de Enfermagem), Joyce de Souza(acadêmica do curso de Enfermagem), Rosemary Torres do Nascimento(acadêmica do curso de Enfermagem), Daniela Cristina Pereira Ramos (acadêmica do curso de Pedagogia), e Vitória Feitosa de Souza (acadêmica do curso de 
História), e tem por objetivo promover a auto-organização das mulheres na luta por direitos, aproximando universidade e comunidade.

Desde 2011, ao longo de várias vigências, o projeto desenvolve ações voltadas para a promoção da saúde da mulher na Zona Norte de Cajazeiras, Paraíba. Durante a vigência no ano de 2016, o projeto promoveu reuniões e desenvolveu ações junto às mulheres da comunidade do bairro Casas Populares, mesmo bairro em que está localizado o CFP/UFCG, e de bairros vizinhos. Os encontros ocorreram na Escola Municipal Cecília Estolano, localizada também no bairro Casas Populares, e discutiu-se com as mulheres uma diversidade de temas relacionados à saúde da mulher numa perspectiva integral. A partir da demanda da própria população, que solicitou a continuidade do Projeto, ele foi renovado para mais uma vigência em 2017.

Tomando como ponto de partida essas informações, este trabalho traz algumas considerações acerca das atividades realizadas na vigência do projeto em 2016, apresentando uma análise das práticas pedagógicas adotadas pelo projeto para garantir seu objetivo,a promoção da auto-organização de mulheres por meio do diálogo sobre a saúde. A presente análise se propõe a discutir as práticas pedagógicas, perspectivas e métodos adotados pelo projeto de extensão na oficina "Saúde da mulher, corpo e sexualidade". Destaca-se a utilização do referencial da educação popular, fundamental em um projeto que promove a auto-organização, ou seja, o desenvolvimento da autonomia de mulheres em situação de risco e vulnerabilidade.

\section{METODOLOGIA}

Para realização deste trabalho desenvolvemos algumas etapas de sistematização dos estudos e experiências: 1. Levantamento bibliográfico sobre abordagens pedagógicas no âmbito da saúde; 2. Análise dos Relatórios de Atividades do Projeto de Extensão "Autoorganização de mulheres e saúde", encaminhados à PROPEX- Pró-Reitoria de Pesquisa e Extensão da UFCG; e 3. Análise da nossa própria experiência enquanto extensionistas do Projeto.

De acordo com o objetivo deste trabalho, o foco de análise escolhido foi a oficina "Saúde da mulher, corpo e sexualidade", realizada em 14 de dezembro de 2016, a partir da 
qual faremos a discussão das práticas pedagógicas, perspectivas e métodos adotados pelo projeto de extensão "Auto-organização de mulheres e saúde.

\section{METÓDOS E ABORDAGENS DA PRATICA EDUCATIVA NA SAÚDE: A IMPORTÂNCIA DA EDUCAÇÃO POPULAR}

Para iniciar a discussão, é importante delimitar os tipos de pedagogias comumente adotadas nas práticas educativas em saúde.

Uma pedagogia inclui mais elementos que puros pressupostos da educação, tais como processo sócio culturais, a concepção psicológica do educando, a forma de organização do processo educacional etc. Porém esses elementos compõem uma pedagogia à medida que estão aglutinados e articulados a partir de um pressuposto de direcionamento filosófico. (LUCKESI, 1994, p.33)

Ressaltando que toda prática educativa é norteada, intencionalmente ou não, por uma tendência pedagógica, percebemos que, ao falar em "pedagogias", estamos lidando com ideologias e concepções filosóficas que perpassam ou são transmitidas pelo processo educativo.

Existem inúmeras pedagogias que podem ser, e são, adotadas pelos profissionais da área da saúde, como a Pedagogia tradicional, a Pedagogia renovada, a Pedagogia de condicionamento e a Pedagogia crítica. Destacaremos a Pedagogia de transmissão, ou tradicional, e a Pedagogia da problematização, crítica ou libertadora, por serem as mais difundidas no meio.

A educação em saúde tradicional, inicialmente chamada de Educação Sanitária, surge no Brasil a partir da necessidade do Estado brasileiro de controlar as epidemias de doenças infecto-contagiosas que ameaçavam a economia agroexportadora do país durante a República Velha, no começo do século XX. Nesse período a população brasileira era atingida por doenças como a varíola, febre amarela, tuberculose e sífilis, que estavam relacionadas às péssimas condições sanitárias e socioeconômicas em que o povo vivia. (MACIEL, 2009, p.774)

Historicamente, a educação em saúde baseadas nas pedagogias tradicionais é uma das primeiras práticas educativas em saúde difundidas no Brasil. Ainda hoje ela é amplamente 
utilizada pelos profissionais da área ao realizarem palestras e outras abordagens instrucionais que têm como objetivo a transmissão de informações sobre determinadas práticas de saúde e prevenção. Trata-seda pedagogia que se fundamenta no método de transmissão do conhecimento.

Entretanto, a realidade mostra-se complexa, e a construção de uma relação do sujeito com o próprio corpo, com o cuidado de si, e com o processo saúde-doença por ele vivenciado, não podem ser promovidos a partir de uma transmissão de informações.

As ações de saúde não implicam somente a utilização do raciocínio clínico, do diagnóstico, da prescrição de cuidados e da avaliação da terapêutica instituída. Saúde não são apenas processos de intervenção na doença, mas processos de intervenção para que o indivíduo e a coletividade disponham de meios para a manutenção ou recuperação do seu estado de saúde, no qual estão relacionados os fatores orgânicos, psicológicos, sócio-econômicos e espirituais. (PEREIRA, 2003, p.1528)

Os indivíduos e a coletividade apenas criarão mecanismos eficazes de resistência e enfrentamento, se forem capazes de formular um saber autônomo sobre determinado problema. Ao contrário da educação tradicional, "depositária", que visa depositar no educando as informações, sem se preocupar com a problematização dessas informações por parte do educando, as pedagogias críticas ou libertadoras, que ganharam espaço na década de 80, vão pensar na mediação do conhecimento.

No âmbito internacional, o Brasil teve um papel pioneiro na constituição do método da Educação Popular, o que explica em parte a sua importância, aqui, na redefinição de práticas sociais dos mais variados campos do saber. Ela começa a se estruturar como corpo teórico e prática social no final da década de 50, quando intelectuais e educadores liga dos à Igreja Católica e influencia dos pelo humanismo personalista que florecia na Europa no pósguerra, se voltam para as questões populares. Paulo Freire foi o pioneiro no trabalho de sistematização teórica da Educação Popular. (VASCONCELOS, 2003, p.20)

A crítica freireana sobre essa pedagogia tradicional, chamada por ele de "bancária", aponta que essa pedagogia não é suficiente para prover uma prática educativa em saúde adequada, que vise à autonomia, pois não é pautada na dialogicidade. 
Na concepção "bancária" que estamos criticando, para a qual a educação é o ato de depositar, de transferir, de transmitir valores e conhecimentos, não se verifica nem pode verificar-se esta superação. Pelo contrário, refletindo a sociedade opressora, sendo dimensão da "cultura do silêncio", a "educação" "bancária" mantém e estimula a contradição. (FREIRE, 1987, p. 34)

Refletindo com base na nossa percepção da realidade, na condição de extensionistas,concordamos com a crítica freireana.As práticas educativas desenvolvidas na nossa experiência de extensão promovem a autonomia dos sujeitos envolvidos no projeto, sendo também contrárias às concepções designadas por Paulo Freire como“messiânicas", que limitam e reduzem o participante a um mero receptor das informações obtidas, e não produz criatividade, nem protagonismo, por não considerarem os saberes dos sujeitos que participam da atividade de extensão.

Daí que, em seu "campo associativo", o termo extensão se encontre em relação significativa com transmissão, entrega doação, messianismo, mecanicismo, invasão cultural, manipulação, etc. E todos existirmos envolvem ações que, transformando o homem em quase "coisa", o negam como um ser de transformação do mundo. Além de negar, como veremos, a formação e a constituição do conhecimento autênticos. Além de negar a ação e a reflexão verdadeiras àqueles que são objetos de tais ações. (FREIRE, 1977, p.13)

Pensamos as ações extensionistas no âmbito da promoção da educação popular em saúde, numa perspectiva que impulsiona o diálogo, estimulando também o desenvolvimento da emancipação, da participação, e criatividade contribuindo assim para a formação da autonomia dos participantes do projeto. Coloca-se em destaque que a proposta de oficina, o planejamento das dinâmicas e a participação dos extensionistas que ainda se encontram em processo de formação profissional, enquanto fatores que contribuíram para estruturar essas práticas de educação em saúde e pensar novas práticas, que garantam a uma melhor qualidade de vida e troca de saberes entre todos os envolvidos. A troca, a descoberta, e a autonomia também são estimuladas entre os extensionistas, pois acreditamos que a participação acadêmica nessas atividades estabelece o reconhecimento do outro, o que também significa colocar-se no lugar dele, para gerar o diálogo que revigora e determina a formulação de novos conhecimentos. 


\section{AUTO-ORGANIZAÇÃO DE MULHERES E SAÚDE: A PERSPECTIVA METODOLÓGICA DAS OFICINAS}

As oficinas promovidas pelo Projeto "Auto-organização de mulheres e saúde"se estruturam por meio de temas geradores,que emergem nos momentos de encontro com as mulheres participantes e são, posteriormente, organizados pela equipe extensionista em uma proposta de oficina específica. Os componentes básicos para realização de oficinas na área da saúde, estabelecidos por Afonso (2003) como aspectos cruciais para seu planejamento: a demanda, o foco, o enquadre e a flexibilidade.

Os temas relacionados ao corpo e à sexualidade são considerados tabus em nossa sociedade por questões históricas e sociais, dificultando, assim, a conversa sobre cuidado e prevenção e trazendo prejuízos à saúde à vivência da sexualidade. Quando o público em questão são as mulheres, o tabu é ainda mais rígido, tornando-se um desafio realizar ações educativas sobre o tema.

Os corpos masculinos e femininos são, pois, o lócus das experiências e vivências sexuais. Eles expressam e refletem as normas, os valores e a moral da sociedade a que pertencem. São corpos físicos carregados de representações sociais e culturais, são sujeitos e objetos nas práticas sexuais (SOUTO; KÜCHEMANN, 2011, p.301)

Desse modo, o corpo é representado a partir das subjetividades construídas em uma sociedade patriarcal. O corpo feminino ainda é visto como algo a ser controlado, e teria como finalidades, paradoxalmente, a função reprodutiva ou o prazer masculino. A sexualidade da própria mulher é, então, reprimida, o que também está relacionado aos padrões estéticos impostos socialmente, sendo a expressão da sexualidade de mulheres que não se encaixem nesse padrão, negadas e/ou invisibilizadas.

Por essas razões, consideramos que a oficina realizada sobre essa temática, no âmbito do projeto de extensão, permite delimitar as abordagens pedagógicas e de mediação do conhecimento promovidas pelo projeto.

A Oficina é um meio de construção do conhecimento, sem perder a associação entre a teoria e a prática. Cuberes apud Vieira e Volquind (2002, p. 11), conceituam-na como sendo "um tempo e um espaço para aprendizagem; um processo ativo de transformação recíproca 
entre sujeito e objeto; um caminho com alternativas, com equilibrações que nos aproximam progressivamente do objeto a conhecer."

A apresentação da temática "Saúde da mulher, corpo e sexualidade", foi sugerida às mulheres, certificando-se de que era uma proposta de oficina acolhida pelo público.Os procedimentos adotados pela equipe para a realização desta oficina foram: abordagem com utilização de dinâmica e introdução do tema; debate com as mulheres na roda de conversa; observação do comportamento das mulheres, como retraimento, ansiedade, curiosidade, etc.;e encerramento do encontro. $\mathrm{O}$ encerramento envolveu uma troca de anéis entre as participantes, representando a nossa união com as mulheres, uma aliança de cuidado e partilha.

Antes da efetivação da ação, o grupo realizou reuniões de planejamento e capacitação para a promoção da ação:

Reunião dia 01.12.2016: Discussão sobre os artigos científicos: Feminismo negro: raça, identidade e saúde reprodutiva no Brasil (1975-1993); Gênero, sexualidade e direitos das mulheres (livro); Nosso Corpo nos pertence: A dialética do biológico e do social; Política Nacional de Atenção Integral à Saúde da Mulher - 2004; Prostituição - uma abordagem feminista; Sexualidade e feminismo. Elaboração para o último encontro, a relação da mulher com o seu corpo, a sua sexualidade e a saúde da mulher. Dinâmica com imagens de revistas na escolha da mulher mais "linda." Fechamento de data para o último encontro e entrega de convites. (SANTOS et al, 2016, p.11)

Por considerarmos um recurso interessante, destacamos o uso das fotografias de revistas como uma técnica para de abertura de diálogos, confirmou-se comouma abordagem educativa interessante, visto que é um recurso amplamente difundido e indicado entre os profissionais da área da educação:

$\mathrm{Na}$ medida em que o senso comum atribui à fotografia o sentido de 'retratação do real', cabe a nós educadores fazemos a mediação entre esse conceito e as concepções que nossos alunos possuem sobre as implicações da manipulação da imagem fotográfica. (CANO, 2009, p.47)

O exercício realizado pela equipe foi da problematização do real e da manipulação da imagem, para produzir a discussão e conhecimento em torno do tema da saúde. Uma 
metodologia de ensino problematizadora. Ao invés de apenas levar imagens sobre as doenças de forma direta e meramente apresentá-las ao público, a equipe utilizou a mediação para trabalhar em conjunto as mulheres sobre o tema saúde e sexualidade. Foram utilizadas imagens de revistas, conhecidas e manuseadas por essas mulheres no seu cotidiano, abordagem característica da proposta da educação popular. Solicitamos que as participantes indicassem quais eram as mulheres lindas naquelas revistas, e as respostas permitiram refletir sobre estereótipos de gênero e padrões de beleza e corpo perfeito impostos às mulheres.

Por meio da análise dos relatórios de vigências anteriores, identificamos a metodologia de rodas de conversa como algo recorrente em todas as atuações do projeto.

As rodas de conversa, metodologia bastante utilizada nos processos de leitura e intervenção comunitária, consistem em um método de participação coletiva de debates acerca de uma temática, através da criação de espaços de diálogo, nos quais os sujeitos podem se expressar e, sobretudo, escutar os outros e a si mesmos. Tem como principal objetivo motivar a construção da autonomia dos sujeitos por meio da problematização, da socialização de saberes e da reflexão voltada para a ação. Envolve, portanto, um conjunto de trocas de experiências, conversas, discussão e divulgação de conhecimentos entre os envolvidos nesta metodologia. (NASCIMENTO; SILVA, 2009, p.1).

As trocas de vivências e a construção do conhecimento coletivo são benefícios marcantes na adoção dessa metodologia, que promove uma maior circulação de conhecimento, além do diálogo aberto entre extensionistas e participantes da oficina.

O público alvo do projeto são mulheres da comunidade da zona norte de Cajazeiras, em sua maioria casada, donas de casa, com baixo nível de escolaridade. A opção pela formulação de oficinas, tendo como base a educação popular, torna-se pertinente, pois atende à realidade dessas mulheres e torna-as também mediadoras do processo de ensino e aprendizagem.

Os temas geradores a exemplo das palavras geradoras de Paulo Freire são temas que mobilizam o grupo por que se relacionam a experiência, tocam em necessidades medos, alegrias conflitos e possibilidades aguçam o desejo de participação e troca. (AFONSO, 2003, p.20) 
Iniciar o diálogo a partir do tema gerador selecionado não significa excluir qualquer possibilidade de novo direcionamento durante a efetivação da ação, esse recorte é utilizado apenas para fundamentar a discussão, de modo que se possa conhecer cada vez mais sobre o tema proposto. Ressaltamos que a ação emergiu do estudo e do conhecimento da comunidade envolvida, pois a equipe desenvolve suas atividades com base em uma percepção sobre a realidade da população:

Considerando ainda que a UFCG Cajazeiras localiza-se em uma região onde há grandes desigualdades sociais e ainda é muito forte o machismo e a divisão sexual do trabalho faz necessário trabalhar junto à comunidade a fim de fomentar a participação popular e o empoderamento feminino. (SANTOS et al ,2017, p.2)

Como pudemos constatar a escolha do tema a ser debatido é uma decisão coletiva, e também leva em consideração nessa escolha à demanda da população, por meio de análise a equipe de facilitadores conseguiu identificar esses enquanto problemas sociais que afligem esse grupo de mulheres atendidas, bem como a necessidade de práticas de intervenção para transformação dessa realidade.

Tais ações demonstram a preocupação do projeto em fomentar oficinas didáticas que propiciem o aprendizado dos envolvidos, ou seja, o método da educação popular orientado pela pedagogia crítica que visa proporcionar às mulheres autonomia sobre a construção de seu conhecimento.

Com base nas rodas de conversas realizadas com as mulheres da comunidade e planejadas pelos extensionistas, evidenciou-se fundamental discutir sobre a autoestima das mulheres, em razão do descrédito que as mesmas possuíam em relação a sua imagem corporal, confluindo para o desequilíbrio na saúde mental, consequência direta do sofrimento psíquico oriundo das relações familiares/afetivas. Assim, com o êxito das atividades nas rodas de conversas, é primordial a continuidade destes debates e discussões para que cada vez mais as mulheres possam concretizar seu empoderamento a partir da sua organização junto a outras mulheres. (MARQUES et al, 2016, p.2) 
Por meio da problematização de imagens e diálogo aberto, a equipe conseguiu construir junto às mulheres conhecimentos referentes à temática "Saúde da mulher, corpo e sexualidade".

\section{RESULTADOS E CONSIDERAÇÕES FINAIS}

As ações educativas em saúde são várias, com diferentes finalidades. O projeto "Autoorganização de mulheres e saúde" tem enquanto objetivo promover uma prática educativa em torno da saúde, não acontecendo como uma prática aleatória, para isso são realizadas escolhas metodológicas, com uma intencionalidade focada nos efeitos esperados dessa ação educativa. A opção pedagógica adotada está diretamente relacionada com o conhecimento do seu público.

Todos os processos educativos, assim como suas respectivas metodologias e meios têm por base uma determinada pedagogia. São extensas e numerosas as práticas educativas na área de saúde, elas estão inseridas na formação dos profissionais trabalhadores da área de saúde e também na educação em saúde da população. As opções pedagógicas adotadas refletem as ideologias e em sua maioria o interesse está nos efeitos de sua aplicação. Assim dizendo, cada opção pedagógica tem conseqüências diferentes sobre a conduta individual e coletiva. (BORDENAVE, 1999, p.163)

Numa perspectiva de sempre ensinar e aprender, na condição de educadores, os profissionais da área da saúde devem refletir sobre sua prática pedagógica, pois seria impossível efetivar uma ação educativa bem sucedida sem uma escolha pedagógica intencional e consciente. Dessa forma, a relação entre educação e saúde beneficia profissionais e pacientes.

A educação e a saúde são espaços de produção e aplicação de saberes destinados ao desenvolvimento humano. Há uma interseção entre estes dois campos, tanto em qualquer nível de atenção à saúde quanto na aquisição contínua de conhecimentos pelos profissionais de saúde. Assim, estes profissionais utilizam, mesmo inconscientemente, um ciclo permanente de ensinar e de aprender. (PEREIRA, 2003, p.1527)

Identificamos o método da educação popular e a pedagogia crítica como importantes norteadores da prática educativa em torno da saúde promovidas pelo projeto "Auto 
Organização de mulheres e saúde". Os resultados obtidos pelo projeto são exitosos, o trabalho desenvolvido tem cada vez mais contado com a participação da comunidade e garantido a formação na área da saúde a mulheres em situação de vulnerabilidade.

Destacamos a importância das práticas interdisciplinares para realização de ações educativas bem fundamentadas na área da saúde, bem como das reflexões pedagógicas por parte dos profissionais da área da saúde, pois estes se descobrem e se forjam educadores ao longo de sua prática.

\title{
SELF-ORGANIZATION OF WOMEN AND HEALTH: AN ANALYSIS ON POPULAR EDUCATION IN HEALTH OFFICES
}

\author{
ABSTRACT
}

We discuss the different pedagogical practices that perpass the extension project "Selforganization of women and health". We developed as methodology the bibliographical survey, analysis of previous project reports, and analysis of the workshop experience "Women's health, body and sexuality". We conclude that the pedagogical practices promoted by the project provide all those involved through popular education the construction of knowledge

KEYWORDS: Popular education; pedagogical practices; Cheers.

\section{AUTO-ORGANIZACIÓN DE MUJERES Y SALUD: UN ANÁLISIS SOBRE LA EDUCACIÓN POPULAR EN OFICINAS DE SALUD}

\section{RESUMEN}

Discurríamos sobre las diferentes prácticas pedagógicas que atravesan el proyecto de extensión "Auto-organización de mujeres y salud". Desarrollamos como metodología el levantamiento bibliográfico, análisis de los informes de vigencias anteriores del proyecto, y análisis de la experiencia del taller "Salud de la mujer, cuerpo y sexualidad". Concluimos que las prácticas pedagógicas promovidas por el proyecto propician a todas las involucradas a través de la educación popular la construcción de saberes.

PALABRAS CLAVES: Educación popular; Prácticas pedagógicas; Salud. 


\section{REFERÊNCIAS BIBLIOGRÁFICAS}

AFONSO, L et al. Oficinas em dinâmica de grupo na área da saúde. Belo Horizonte: Edições do Campo Social, 2003.

ALBERTI, Gabriela Fávero et al. Educação popular trabalhada em oficinas de saúde: a sexualidade durante o adolescer. Revista de Educação Popular, v. 13, n. 1, p. 75-81, 2014. BORDENAVE, J.E.D. Alguns fatores pedagógicos. In: SANTANA, J.P. et al. Capacitação em Desenvolvimento de Recursos Humanos CADRHU. Natal: Ministério da Saúde/Organização Pan-Americana da Saúde/ Editora da UFRN; 1999.

BRASIL. Ministério da Saúde. Secretaria de Gestão Estratégica e Participativa. Caderno de educação popular e saúde. Brasília: Ministério da Saúde, 2007.p.160

FREIRE, P. Pedagogia do oprimido. Rio de Janeiro: Paz e Terra, 1987.

FREIRE, P.. Extensão ou comunicação. São Paulo: Paz e Terra, 1977.

LUCKESI, C. C.. Filosofia da Educação. São Paulo: Cortez Editora, 1994.

MACIEL, M.E.D. Educação em saúde: conceitos e propósitos. Cogitar: Infere. 2009.

MARQUES, M. et al. Auto-organização de mulheres e saúde.In: IX Encontro de Extensão Universitária: ampliando conhecimentos e promovendo o desenvolvimento regional, 2016 ,Cajazeiras.Anais.Cajazeiras:UFCG,2016.v.4.Disponívelem:<http://extensao.ufcg.edu.br/publ icacoes/2016/resumos/ixenexufcg_3476>. Acesso em: 04 de julho de 2017.

NASCIMENTO, M. A. G.; SILVA, C. N. M.. Rodas de conversas e oficinas temáticas: Experiências metodológicas de ensino- aprendizagem em geografia. In: $10^{\circ}$ Encontro Nacional de Prática de Ensino em Geografia (ENPEG). Porto Alegre, ago./set, 2009. Disponível em: http://www.agb.org.br/XENPEG/artigos/Poster/P\%20\%2836\%29.pdf .Acesso em:30 de julho de 2017.

PEDROSA, J.I.S. Educação Popular no Ministério da Saúde: identificando espaços e referências. In: Ministério da Saúde. Secretaria de Gestão Estratégica e Participativa. Departamento de apoio à Gestão Participativa. Caderno de Educação Popular e Saúde. Brasília: Ministério da Saúde; 2007.

PEREIRA, A. L.. As tendências pedagógicas e a prática educativa nas ciências da saúde. Caderno de. Saúde Pública, v. 19, n. 5, p. 1527-1534, 2003. Disponível em: http://www.scielo.br/pdf/csp/v19n5/17825. Acesso em: 30 de julho de 2017. 
SANTOS, S.et al. Auto-organização de mulheres e saúde.Relatório de atividades .2016. Disponível em:〈http://extensao.ufcg.edu.br/publicacoes/2016/resumos/ixenexufcg_3476>. Acesso em: 04 de julho de 2017.

SOUTO, Kátia; KUCHEMANN, Berlindes Astrid. Representações sociais de corpo e sexualidade de profissionais de saúde que atendem mulheres com HIV e AIDS. Revista Tempus Actas de Saúde Coletiva, v. 5, n. 1, p. 295-309, 2011.

STOTZ, E.N. Enfoques sobre educação popular e saúde. In: Ministério da Saúde. Caderno de educação popular e saúde. Brasília: Ministério da Saúde; 2007. p. 46-57.

VASCONCELOS, E.M. Educação popular: instrumento de gestão participativa dos serviços de saúde. In: Ministério da Saúde. Secretaria de Gestão Estratégica e Participativa. Departamento de apoio à Gestão Participativa. Caderno de educação popular e saúde. Brasília: Ministério da Saúde; 2007. p. 18-30

VIEIRA, Elaine; VOLQUIND, L.. Oficinas de ensino: O quê? Por quê? Como? 4. ed. Porto Alegre: Edipucrs, 2002. 